\title{
Analisa dan Implementasi Wireless Extension Point dengan SSID (Service Set Identifier)
}

\author{
Riska $^{1}$, Prama Wira Ginta ${ }^{2}$, Patrick $^{3}$ \\ ${ }^{1,2}$ Program Studi Sistem Komputer, Universitas Dehasen Bengkulu \\ Email : riska.iskandar@unived.ac.id
}

\begin{abstract}
This research aims to apply wireless extension point in computer network with one SSID. Build 2 pieces of wireless or access points with one SSID. Reduce the number of SSIDs that are being tested in computer network services, especially wireless LAN networks. This research uses expriment research method. In this research, the implementation and experiments on how to install and configure the wireless router and range extender so that later all wireless or access point will have the same SSID that will allow all the clients connected in the network to connect without choosing the existing SSID. The results of this implementation will be documented so as to get the proper analysis to build wireless extension point. This research shows that the benefit of the addition of range extender that has the function of connecting signal from wireless router. So for the connection is no longer required pengkoneksian again if it has moved from the wireless router.
\end{abstract}

Keywords: Aextension point, wifi, network, SSID

Intisari-Penelitian ini bertujuan untuk Menerapkan wireless extension point dalam jaringan komputer dengan satu SSID. Membangun 2 buah wireless atau access poin dengan satu SSID.Mengurangi banyaknya SSID yang tesedian dalam layanan jaringan komputer khususnya jaringan wireless LAN. Penelitian ini menggunakan metode penelitian eksprimen. Pada penelitian ini dilakukan implementasi dan percobaan mengenai cara instalasi dan konfigurasi wireless router dan range extender sehingga nantinya semua wireless atau access point akan memiliki SSID yang sama yang akan memudahkan semua client yang terhubung dalam jaringan untuk terkoneksi tanpa memilih SSID yang ada. Hasil dari implementasi ini nantinya akan didokumentasikan sehingga mendapatkan analisa yang tepat untuk membangun wireless extension point. Penelitian ini terlihat bahwa manfaat dari penambahan range extender yang mempunyai fungsi sebagai penyambung sinyal dari wireless router. Sehingga untuk koneksi tidak diperlukan lagi pengkoneksian ulang jika telah berpindah tempat dari wireless router.

Kata kunci : extension point, wifi, jaringan, SSID

\section{PENDAHULUAN}

Teknologi informasi yang berkembang pesat saat ini, diikuti juga dengan berkembangnya produk elektronik sebagai media dari teknologi informasi itu sendiri. Dengan semakin pesatnya perkembangan ini, maka sewajarnya banyak instansi baik itu instansi pemerintahan maupun instansi swasta yang juga sudah mulai melakukan upgrade terhadap perangkat pendukung dari sebuah teknologi informasi ini.

Salah satu perkembangan teknologi informasi yang pesat saat ini adalah jaringan wireless atau nirkabel dan biasa juga disebut wifi, dari segi jangkauan teknologi wireless ini sudah mampu mencapai 50 - 100 meter tentunya dengan jangkauan seperti itu, maka diperlukan banyak wireless atau access point. Dengan terdapat banyak wireless, berarti banyak pula SSID yang digunakan. Untuk mengatasi banyaknya SSID ini, maka dengan menggunakan teknologi wireless extension point akan membuat semua wireless yang terhubung dalam satu jaringan komputer hanya memiliki satu SSID saja.

Dengan adanya wireless extension point ini diharapkan client yang terhubung dalam jaringan tidak bingung lagi mencari SSID mana atau access point mana yang akan digunakan, karena semua access point akan memiliki SSID atau nama yang sama. Selain itu, dengan adanya SSID yang sama ini client dalam jaringan komputer tidak perlu lagi mengkoneksikan ulang wireless di clientnya jika berpindah tempat.

Berdasarkan latar belakang diatas, maka penulis merasa tertarik untuk mengangkat judul "Ana- 
lisa dan Implementasi Wireless Extension Point dengan SSID (Service Set Identifier)".

\section{LANDASAN TEORI}

\section{A. Pengertian Analisa}

Analisis penelitian suatu peristiwa atau kejadian (karangan, perbuatan, dsb) untuk mengetahui keadaan yang sebenarnya (sebab-musabab, duduk perkaranya, dsb). Kamus Besar Bahasa Indonesia, Edisi III (2001). Analisis adalah aktivitas yang memuat sejumlah kegiatan seperti mengurai, membedakan, memilah sesuatu untuk digolongkan dan dikelompokkan kembali menurut kriteria tertentu kemudian dicari kaitannya dan ditafsir maknanya. (Makinuddin \& Tri, 2006:40).

Menurut Wikipedia (2013:1) dalam linguistik, analisa atau analisis adalah kajian yang dilaksanakan terhadap sebuah bahasa guna meneliti struktur bahasa tersebut secara mendalam. Sedangkan pada kegiatan laboratorium, kata analisa atau analisis dapat juga berarti kegiatan yang dilakukan di laboratorium untuk memeriksa kandungan suatu zat dalam cuplikan. Namun, dalam perkembangannya, penggunaan kata analisa atau analisis mendapat sorotan dari kalangan akademisis, terutama kalangan ahli bahasa. Penggunaan yang seharusnya adalah kata analisis. Hal ini dikarenakan kata analisis merupakan kata serapan dari bahasa asing (inggris) yaitu analisys. Dari akhiran -isys bila diserap ke dalam bahasa Indonesia menjadi -isis. Jadi sudah seharusnya bagi kita untuk meluruskan penggunaan setiap bahasa agar tercipta praktik kebahasaan yang baik dan benar demi tatanan bangsa Indoesia yang semakin baik.

Menurut Hidayat (2007 : 266), analisis adalah kemampuan pemecahan masalah subjek kedalam elemen-elemen konstituen, mencari hubunganhubungan internal dan diantara elemen-elemen, serta mengatur format-format pemecahan masalah secara keseluruhan yang ada pada akhirnya menjadi sebuah nilai-nilai ekspektasi. Daya analisis juga merupakan gambaran dari abilitas dalam fungsi-fungsi mencirikhaskan fakt-fak- ta yang berbasis pada hipotesis yang dibangun. Serta abilitas dalam fungsi-fungsi evaluasi material-material yang bersifat ekstrak dan kompleks. Daya analisis dapat mempertegas asumsi-asumsi pemecahan masalah-masalah yang ada. Identifikasi pemecahan masalah tersebut akan diakhiri dengan kesimpulan yang dibangun kedalam susunan pernyataan-pernyataan yang jauh lebih tegas dan pasti.

\section{B. Implementasi}

Implementasi adalah proses kurikulum yang lebih rumit dibandingkan konstruksi kurikulum. Dalam implementasi berbagai faktor berpengaruh terhadap implementasi. (Said, 2007:137).

Implementasi adalah tahap ketika mengaplikasikan rencana asuhan ke dalam bentuk intervensi guna membantu klien mencapai tujuan yang telah diteteapkan. Implementasi adalah kemampuan komunikasi yang efektif, kemampuan untuk menciptakan hubungan saling percaya dan saling bantu, kemampuan melakukan teknik psikomotor, kemampuan melakukan observasi sistematis, kemampuan memberikan pendidikan kesehatan, kemampuan advokasi, dan kemampuan evaluasi. (Asmadi, 2008:177).

\section{Wireless}

Menurut Sofana (2013 : 330), wireless atau wireless network merupakan sekumpulan komputer yang saling terhubung antara satu dengan lainnya sehingga terbentuk sebuah jaringan komputer dengan menggunakan media udara atau gelombang sebagai jalur lintas datanya.

\section{1) Pengertian Wireless}

Wireless Local Area Network pada dasarnya sama dengan jaringan Local Area Network yang biasa kita jumpai. Hanya saja, untuk menghubungkan antara node device antar client menggunakan media wireless, chanel frekuensi serta SSID (Service Set Identifier) yang unik untuk menunjukkan identitas dari wireless device. Wireless merupakan salah satu jaringan komputer lokal 
yang memanfaatkan gelombang radio sebagai media transmisi data. (Sofana, 2013:330).

Teknologi wireless adalah salah satu pilihan yang tepat untuk menggantikan teknologi jaringan yang terdiri dari banyak kabel dan sebuah solusi akibat jarak antar jaringan yang tidak mungkin dihubungkan melalui kabel. (Ahmad, 2007:26).

Jaringan wireless menggunakan gelombang radio (Radio Frequency/RF) atau gelombang mikro untuk melangsungkan komunikasi antar perangkat jaringan komputer. Jaringan wireless merupakan alternative yang lebih modern untuk melakukan interkoneksi dibandingkan dengan jaringan kabel biasa yang menggunakan kabel tembaga serat optik. (Edi, 2005:42).

\section{2) Sejarah Perkembangan Wireless}

Sejarah perkembangan teknologi jaringan wireless hingga saat ini dapat dibagi menjadi 3 genersi, yaitu generasi pertama ( $1 \mathrm{G})$, generasi kedua $(2 \mathrm{G})$, dan generasi ketiga $(3 \mathrm{G})$. (Wilman \& Riyan, 2006:2).

Generasi pertama dimulai pada akhir tahun 1970-an di Amerika Serikat. Perangkat wireless yang digunakan pada saat itu adalah Advanced Mobile Phone Service (AMPS) dan di-launching pertama kali di New Jersey dan Chicago pada tahun 1978.

Generasi kedua (2G) telepon wireless dipelopori oleh Eropa untuk menciptakan standar bersama dalam satu sistem jaringan yang berlaku di seluruh kawasan Eropa.

Sistem komunikasi bergerak generasi ketiga (3G) lebih mengekploitasi kemampuan multimedia. Termasuk pengiriman foto digital. Akses video digital, penjelajahan internet tanpa kabel, dan tentu saja hubungan suara seperti biasanya.

Pada tahun 2002, IEEE membuat spesifikasi baru yang dapat menggabungkan kelebihan 802.11 b dan 802.11a. Spesifikasi kode 802.11g yang bekerja pada frekuensi $2,4 \mathrm{GHz}$ dengan teori kecepatan transfer data hingga 54Mbps. Peralatan $802.11 \mathrm{~g}$ kompatibel dengan $802.11 \mathrm{~b}$, sehingga dapat saling komunikasi. Misal, sebuah komputer yang menggunakan jaringan kartu 802.11g dapat memanfaatkan akses point $802.11 \mathrm{~b}$, dan sebaliknya. Spesifikasi dari 802.11 dapat dilihat pada Tabel 1.

\section{3) Komponen Wireless}

Ada beberapa komponen yang dibutuhkan dalam sebuah jaringan wireless atau nirkabel terdiri atas empat komponen utama, yakni wireless card, wireless router atau wireless access point, extension point, koneksi internet dan antena. (Enterprise, 2010:5).

a) Wireless Card, Wireless card ini digunakan untuk menagkap sinyal yang dikirim ke bagian ini sehingga diperoleh penggunaan yang lebih lengkap bila dibandingkan dengan beberapa penggunaan lainnya.

b) Wireless Router atau wireless access point, adalah perangkat yang berperan penting dalam sebuah jaringan wireless, bertugas mengatur dan menghubungkan koneksi beberapa peralatan WiFi. Wireless router ini dikenal juga dengan nama wireless broadband router atau access point. Pada WLAN, alat untuk mentransmisikan data disebut dengan Access Point dan terhubung dengan jaringan LAN melalui kabel. Fungsi dari Acces Point adalah mengirim dan menerima data, sebagai buffer data antara WLAN dengan Wired LAN, mengkonversi sinyal frekuensi radio (RF) menjadi sinyal digital yang akan disalurkan melalui kabel atau disalurkan ke perangkat WLAN yang lain dengan dikonversi ulang menjadi sinyal frekuensi radio.

c) Extension Point, berfungsi layaknya repeater untuk client di tempat yang lebih jauh. Untuk mengatasi berbagai problem khusus dalam topologi jaringan, designer dapat menambahkan extension point untuk memperluas cakupan jaringan.

\section{4) SSID atau ESSID}

SSID atau service set indentifier merupakan network ID atau nama untuk jaringan wireless. Beberapa vendor menyebut SSID sebagai doma- 
Tabel 1. Spesifikasi 802.11

\begin{tabular}{|l|l|}
\hline $\begin{array}{c}\text { Spesifi- } \\
\text { kasi }\end{array}$ & \multicolumn{1}{|c|}{ Keterangan } \\
\hline 802.11 & $\begin{array}{l}\text { Spesifikasi WLAN yang pertama, dibuat tahun 1997. Kecepatan transfer data maksimal } \\
\text { yang dapat dicapai sebesar 2Mbps. }\end{array}$ \\
\hline $802.11 \mathrm{a}$ & $\begin{array}{l}\text { Dibuat tahun 1999. Menggunakan frekuensi 5GHz dan kecepatan transfer data maksimal } \\
54 \mathrm{Mbps} .\end{array}$ \\
\hline $802.11 \mathrm{~d}$ & Dibuat tahun 2001. Spesifikasi ini dipakai untuk pengaturan spectrum sinyal. \\
\hline $802.11 \mathrm{f}$ & Dibuat tahun 2003. Merupakan standar bagi protocol komunikasi antar-access point. \\
\hline $802.11 \mathrm{i}$ & Dibuat tahun 2004. Pengembangan 802.11 dengan dukungan security. \\
\hline $802.11 \mathrm{j}$ & $\begin{array}{l}\text { Dibuat tahun 2004. Pengembangan sinyal 5GHz dan mendukung regulasi yang diterapkan } \\
\text { oleh Negara Jepang. }\end{array}$ \\
\hline $802.11 \mathrm{n}$ & $\begin{array}{l}\text { Ditujukn untu WLAN dengan kecepatan transfer data 108Mbps. Di pasar dapat dijumpai } \\
\text { dengan merk dagang MIMO atau Pre-802.11n. }\end{array}$ \\
\hline
\end{tabular}

in ID. Setiap jaringan $W i-F i$ harus memiliki SSID yang unik. Peralatan Wi-Fi yang menggunakan SSID yang sama akan dianggap 1 jaringan.

\section{Pengertian Jaringan Komputer}

Jaringan komputer (computer networks) adalah himpunan interkoneksi sejumlah komputer autonomous. Kata "autonomous" mengandung pengertian bahwa komputer tersebut memiliki kendali atas dirinya sendiri. Jaringan komputer dapat dikatakan sebagai kumpulan beberapa buah komputer yang terhubung satu sama lain dan dapat saling berbagi resources. (Sofana, 2011:4).

Sebuah jaringan lebih dari sekedar pertukaran data antara dua atau beberapa komputer yang terhubung oleh kabel (atau koneksi radio). Sehingga antar kedua komputer tersebut bisa ada pertukaran komunikasi. Ini karena komputer sendiri bisa melakukan pertukaran komunikasi. (Winarno, Ali Zaki \& SmithDev Community, 2013:1).

Dari hasil definisi jaringan komputer diatas dapat di simpulkan bahwa jaringan komputer adalah hubungan antara komputer yang dikoneksikan menggunakan kabel atau nirkabel (wireless) supaya bisa terkoneksi dan saling berkomunikasi.

\section{E. Fungsi Jaringan Komputer}

Jaringan komputer (computer network) atau sering disebut jaringan merupakan dua buah simpul (umumnya berupa komputer) atau lebih ditujukan untuk melakukan pertukaran data atau untuk melakukan bagi pakai perangkat lunak, perangkat keras, dan bahkan berbagi kekuatan pemrosesan.

Berbagi perangkat keras. Perangkat semacam hardisk, printer, CD-ROM, drive, dan bahkan modem dapat digunakan oleh sejumlah komputer tanpa perlu melepas dan memasang kembali. Peranti cukup dipasang pada sebuah komputer atau dihubungkan ke suatu peralatan khusus dan semua komputer dapat mengaksesnya, sehingga cara ini dapat menghemat biaya.

Berbagi program atau data. Program ataupun data dimungkinkan untuk disimpan pada sebuah komputer yang bertindak sebagai server (melayani komputer-komputer yang akan membutuhkan data atau program). Penempatan data pada server juga memberikan keuntungan antara lain menghindari duplikasi ketidak konsistenan.

Mendukung kecepatan berkomunikasi. Dengan adanya dukungan jaringan komputer, komunikasi dapat dilakukan lebih cepat. Para pemakai komputer dapat mengirim surat elektronik dengan mudah dan bahkan dapat bercakap-cakap secara langsung melalui tulisan (chating) ataupun telekonfrensi.

Memudahkan Pengaksesan Informasi. Jaringan komputer memudahkan pengaksesan informasi. Seorang dapat bepergian kemana saja dan tetap dapat mengakses data yang terdapat pada 
server ketika ia membutuhkannya.

\section{F. Protokol TCP/IP}

TCP / IP adalah salah satu perangkat lunak jaringan komputer (networking software) yang terdapat dalam sistem, dan dipergunakan dalam komunikasi data dalam local area network (LAN) maupun Internet. (Sofana, 2013:94). TCP singkatan dari Transmission Control Protocol dan IP singkatan dari Internet Protocol. TCP/IP menjadi satu nama karena fungsinya selalu bergandengan satu sama lain dalam komunikasi data.

TCP/IP saat ini dipergunakan dalam banyak jaringan komputer lokal (LAN) yang terhubung ke Internet, karena memiliki sifat:

1. Merupakan protokol standar yang terbuka, gratis dan dikembangkan terpisah dari perangkat keras komputer tertentu. Karena itu protokol ini banyak didukung oleh vendor perangkat keras, sehingga $\mathrm{TCP} /$ IP merupakan pemersatu perangkat keras komputer yang beragam merek begitu juga sebagai pemersatu berbagai perangkat lunak yang beragam merk sehingga walau memakai perangkat keras dan perangkat lunak komputer yang berlainan, komputer dan komputer lainnya dapat berkomunikasi data melalui Internet.

2. Berdiri sendiri dari perangkat keras jaringan apapun. Sifat ini memungkinkan TCP/ IP bergabung dengan banyak jaringan komputer. TCP/IP bisa beroperasi melalui sebuah Ethernet, sebuah saluran dial-up, dan secara virtual melalui berbagai media fisik transmisi data.

3. Bisa dijadikan alamat umum sehingga tiap perangkat yang memakai TCP/IP akan memiliki sebuah alamat unik dalam sebuah jaringan komputer lokal, atau dalam jaringan kumputer global seperti Internet.

\section{G. Model OSI}

\section{1) Macam-macam Lapisan OSI}

Model referensi jaringan terbuka OSI atau
OSI Reference Model for open networking adalah sebuah model arsitektural jaringan yang dikembangkan oleh badan International Organization for Standardization (ISO) di Eropa pada tahun 1977.

OSI sendiri merupakan singkatan dari Open System Interconnection. Model ini disebut juga dengan model "Model tujuh lapis OSI" (OSI seven layer model). (Sofana, 2013:79).

Struktur tujuh lapis model OSI, bersamaan dengan protocol data unit pada setiap lapisan OSI Reference Model memiliki tujuh lapis, seperti pada tabel 2 .

Layer-layer tersebut disusun sedemikian sehingga perubahan pada satu layer tidak membutuhkan perubahan pada layer lain. Layer teratas (5, 6 and 7) adalah lebih cerdas dibandingkan dengan layer yang lebih rendah; Layer Application dapat menangani protocol dan format data yang sama yang digunakan oleh layer lain, dan seterusnya. Jadi terdapat perbedaan yang besar antara layer Physical dan layer Application.

\section{H. Komputer}

Menurut Sutono (2010 : 1), komputer dapat didefinisikan sebagai kumpulan rangkaian elektronik yang berfungsi untuk menerima input, mengolahnya dan menghasilkan suatu output. Input dapat berasal dari keyboard, mouse, dan perangkat lainnya. Pengelolah input berupa CPU yang terdiri dari prosesor, motherboard, memori dan harddisk drive. Output yang dihasilkan dapat berupa gambar visual yang ditampilkan di layar monitor, printer (hasil cetakan), speaker dan media lainnya.

Menurut Mulyono (2008:1), komputer adalah seperangkat alat elektronik yang terdiri atas peralatan input, alat yang mengolah input, dan peralatan output yang memberikan informasi, serta bekerja secara otomatis. Literatur terbaru menggolongkan komputer berdasarkan empat hal, yaitu data yang diolah, penggunaaan, bentuk dan ukuran, serta generasinya. 
Tabel 2. Tabel model OSI

\begin{tabular}{|c|c|c|}
\hline $\begin{array}{c}\text { Lapisan } \\
\text { ke- }\end{array}$ & Nama lapisan & Keterangan \\
\hline 7 & Application laver & $\begin{array}{l}\text { Berfungsi sebagai antarmuka dengan aplikasi dengan fungsionalitas } \\
\text { jaringan, mengatur bagaimana aplikasi dapat mengakses jaringan, } \\
\text { dan kemudian membuat pesan-pesan kesalahan. Protokol yang bera- } \\
\text { da dalam lapisan ini adalah HTTP, FTP, SMTP, dan NFS. }\end{array}$ \\
\hline 6 & Presentation layer & $\begin{array}{l}\text { Berfungsi untuk mentranslasikan data yang hendak ditransmisikan } \\
\text { oleh aplikasi ke dalam format yang dapat ditransmisikan melalui ja- } \\
\text { ringan. Protokol yang berada dalam level ini adalah perangkat lunak } \\
\text { redirektor (redirector software), seperti layanan Workstation (dalam } \\
\text { Windows NT) dan juga Network shell (semacam Virtual Network } \\
\text { Computing (VNC) atau Remote Desktop Protocol (RDP). }\end{array}$ \\
\hline 5 & Session layer & $\begin{array}{l}\text { Berfungsi untuk mendefinisikan bagaimana koneksi dapat dibuat, } \\
\text { dipelihara, atau dihancurkan. Selain itu, di level ini juga dilakukan } \\
\text { resolusi nama. }\end{array}$ \\
\hline 4 & Transport layer & $\begin{array}{l}\text { Berfungsi untuk memecah data ke dalam paket-paket data serta } \\
\text { memberikan nomor urut ke paket-paket tersebut sehingga dapat di- } \\
\text { susun kembali pada sisi tujuan setelah diterima. Selain itu, pada level } \\
\text { ini juga membuat sebuah tanda bahwa paket diterima dengan sukses } \\
\text { (acknowledgement), dan mentransmisikan ulang terhadp paket-paket } \\
\text { yang hilang di tengah jalan. }\end{array}$ \\
\hline 3 & Network layer & $\begin{array}{l}\text { Berfungsi untuk mendefinisikan alamat-alamat IP, membuat header } \\
\text { untuk paket-paket, dan kemudian melakukan routing melalui in- } \\
\text { ternetworking dengan menggunakan router dan switch layer-3. }\end{array}$ \\
\hline 2 & Data-link layer & 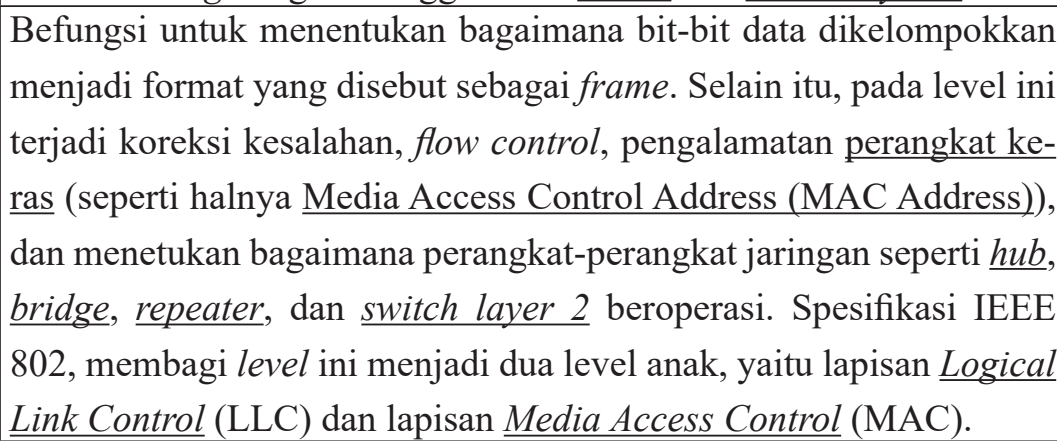 \\
\hline 1 & Physical layer & $\begin{array}{l}\text { Berfungsi untuk mendefinisikan media transmisi jaringan, metode } \\
\text { pensinyalan, sinkronisasi bit, arsitektur jaringan (seperti halnya Et- } \\
\text { hernet atau Token Ring), topologi jaringan dan pengabelan. Selain } \\
\text { itu, level ini juga mendefinisikan bagaimana Network Interface Card } \\
\text { (NIC) dapat berinteraksi dengan media kabel atau radio. }\end{array}$ \\
\hline
\end{tabular}




\section{METODOLOGI PENELITIAN}

\section{A. Tempat dan Waktu Penelitian}

Penelitian dilakukan pada Pusat Komputer (PUSKOM) Universitas Dehasen Bengkulu. Penelitian ini dilakukan dengan dua tahap yaitu : 1) Pra - penelitian ini dilakukan dari bulan Agustus 2014 sampai dengan bulan September 2014, dan 2) Penelitian ini dilakukan pada bulan Oktober 2014.

\section{B. Metode Penelitian}

Metode penelitian yang digunakan adalah metode eksprimen. Pada penelitian ini dilakukan implementasi dan percobaan mengenai cara instalasi dan konfigurasi wireless router dan range extender sehingga nantinya semua wireless atau access point akan memiliki SSID yang sama yang akan memudahkan semua client yang terhubung dalam jaringan untuk terkoneksi tanpa memilih SSID yang ada. Hasil dari implementasi ini nantinya akan didokumentasikan sehingga mendapatkan analisa yang tepat untuk membangun wireless extension point.

\section{Instrumen Perangkat Lunak dan Perangkat Keras}

Dalam pembuatan komputer monitoring server dan notifikasi melaui sms (short message service), alat dan bahan yang digunakan meliputi perangkat lunak (Software), dan perangkat keras (Hardware).

\section{1) Perangkat Lunak (Software)}

Adapun perangkat lunak (software) yang digunakan dalam penelitian ini adalah software default dari wireless router dan range extender.

\section{2) Perangkat Keras (Hardware)}

Adapun spesifikasi dari perangkat keras (hardware) dapat dilihat pada tabel 3 .

Tabel 3. Perangkat keras (hardware)

\begin{tabular}{|c|l|ll|}
\hline No & Jenis & Spesifikasi & \\
\hline 1 & Wireless Router & TP-LINK & TL- \\
& & WA7210N & \\
\hline 2 & Wireless Range & TP-LINK & TL- \\
& Extender & WA730RE & \\
\hline \hline 3 & Client 1 & Notebook Acer & \\
\hline
\end{tabular}

\section{Metode Perancangan Sistem}

\section{1) Blok Diagram Global}

Blok diagram global yang digunakan dalam perancangan penelitian ini adalah sebagai berikut.

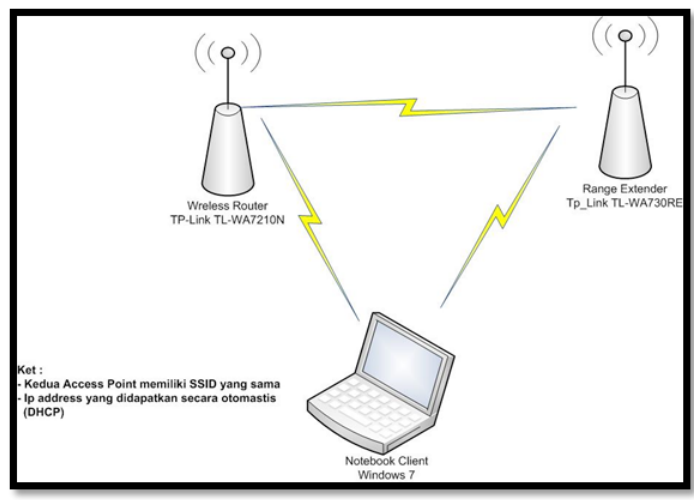

Gambar 1. Blok Diagram Global

Pada gambar 1, wireless router dihubungkan dengan sumber internet agar dapat terkoneksi ke internet, sedangkan range extender dihubungkan dengan wireless router dan menggunakan SSID dari wireless router. Pada konfigurasi ini akan memungkinkan notebook client akan mendapatkan sinyal dari kedua access point tanpa harus mengkoneksikan ulang ke access point yang lain.

\section{2) Prinsip Kerja Sistem}

Wireless router ini bekerja untuk membagi sinyal wireless atau wifi untuk menghubungkan client dengan internet atau intranet. Range externter ini juga memiliki prinsip kerja yang sama dengan wireless router, tetapi range extender ini memperoleh koneksi bukan melalui kabel, melainkan memanfaatkan sinyal wireless dan nantinya akan terhubung ke wireless router dan menjadi repeater sehingga SSID dr range extender sama seperti SSID pada wireless router.

\section{3) Rencana Kerja Sistem}

Rencana kerja wireless extension point dalam jaringan komputer adalah sebagai berikut : 


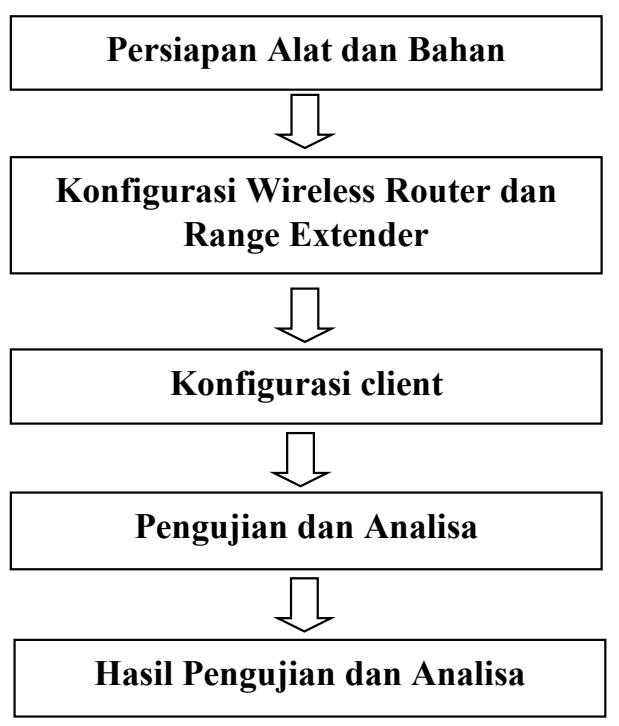

Gambar 2. Rencana Kerja

1. Persiapan alat dan bahan. Adapun alat dan bahan yang harus disiapkan, antara lain sebagai berikut (a) perangkat keras PC / Notebook (b) Tang Crimping (c) Kabel UTP beserta konektornya (d) Wireless router Tp-Link TLWA7210N dan Range Extender TP-Link TLWA730RE

2. Konfigurasi Konfigurasi Wireless Router dan Range Extender. Adapun konfigurasi yang dilakukan pada tahap ini adalah sebagai berikut (a) Setting IP address pada Wireless Router (b) Setting IP adress pada Range Extender (c) Setting SSID yang sama pada wireless router dan range extender. (d) Konfigurasi sistem wireless router dan range extender.

3. Konfigurasi client. Proses yang dilakukan pada tahapan ini adalah mengatur agar client dapat menerima IP address secara dinamic atau secara otomatis.

4. Pengujian dan Analisa. Adapun pengujian dan analisa yang dilakukan pada penelitian ini adalah sebagai berikut : (a) Koneksi SSID apakah jika sudah berpindah tempat harus koneksi ulang atau tidak. (b) Jangkauan sinyal wireless (c) Troubleshooting yang terjadi

5. Hasil Pengujian. Pada tahapan ini, merupakan hasil dari pengujian dan analisa yang dilakukan yang nantinya akan disajikan dalam bentuk tabel pengujian.

\section{4) Perancangan Pengujian}

Pengujian ini dilakukan dengan metode blackbox, yaitu sebuah metode yang digunakan untuk menemukan kesalahan dan mendemonstrasikan fungsional aplikasi saat dioperasikan, apakah input diterima dengan benar dan output yang dihasilkan telah sesuai dengan yang diharapkan, sehingga dapat membuktikan kebenarannya.

\section{HASIL DAN PEMBAHASAN}

\section{A. Hasil}

Berdasarkan penguraian pada bab sebelumnya tentang rencana kerja dalam penelitian ini, pada bab ini akan dijelaskan mengenai hasil dari penelitian yang penulis lakukan. Adapun gambaran umum dari hasil yang penulis lakukan pada penelitian ini adalah sebagai berikut.

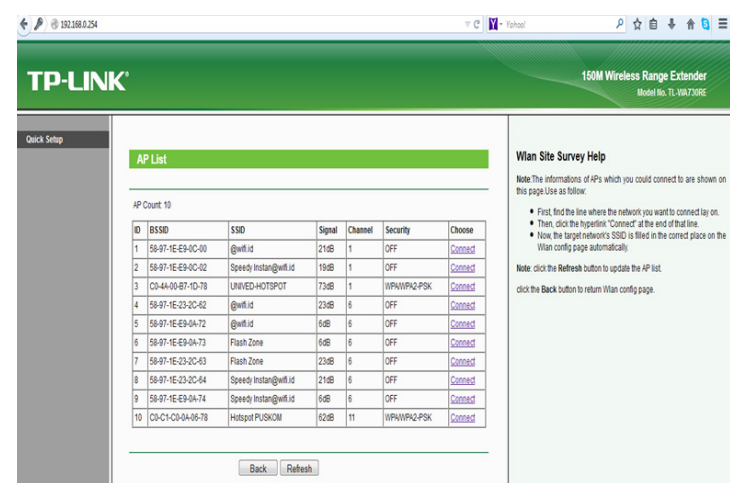

Gambar 3. Hasil wireless extension point

Pada gambar diatas dapat dilihat bahwa range extender dapat memperoleh koneksi dari wireless router yang dibuat tadi, untuk selanjutnya akan dikoneksikan dan disebarkan ulang melalui range extender sebagai extension point sehingga jangakauan sinyal dari wireless router menjadi bertambah atau dengan katan lain akan memperkuat sinyal yang ada pada wireless router tersebut.

\section{B. Pembahasan}

Pada subbab ini akan dibahas mengenai alur kerja yang akan dilakukan pada penelitian ini. Adapun rencana kerja pada penelitian ini adalah 
sebagai berikut :

\section{1) Persiapan Alat dan Bahan}

Adapun alat dan bahan yang harus di persiapkan, antara lain sebagai berikut : (a) Wireless Outdoor Acces Point TP-LINK WA7210N (b) Wireless Range Extender TP-LINK WA730RE (c) PC atau Laptop (d) Kabel UTP (e) Konektor (f) Tang Crimmping (g) Hub/switch

\section{2) Konfigurasi Wireless Outdoor Acces Point TP-LINK WA7210N}

Pada sesi ini kita bisa mengkonfigurasi Wireless Outdoor Acces Point TP-LINK WA7210N terlebih dahulu sebelum digunakan sebagai root Acces Point dengan SSID yang sama nantinya.

\section{3) Konfigurasi Wireless Range Extender TP- LINK WA730RE}

Setelah konfigurasi yang ada pada root Acces Point selesai, selanjutnya melakukan konfigurasi pada Wireless Range Extender berikut ini yang mana nantiya akan digunakan sebagai penyambung jangkuan area Acces Point pertama yang sudah tidak terjangkau lagi. Proses yang dilakukan hampir sama dengan konfigurasi pada acces point sebelumnya.

\section{4) Konfigurasi Client}

Konfigurasi yang dilakukan pada tahapan ini adalah mengatur agar client dapat menerima IP address secara dinamic atau secara otomatis.

\section{Hasil Pengujian \\ 1) Pengujian SSID}

Pengujian ini dilakukan untuk mengetahui apakah perlu melakukan koneksi ulang atau tidak setelah berpindah tempat. Pengujian dilakukan pada:

Pada Wireless Router. Acces point yang di sediakan dari wireless router bernama "UNIVEDHOTSPOT" untuk pertama kalinya diperlukan koneksi.

Pada Range Extender. Acces point yang di se- diakan dari range extender juga bernama "UNIVED-HOTSPOT" dan tidak perlu melakukan koneksi ulang karena sebelumnya sudah terkoneksi dari wireless router.

\section{2) Jangkauan Sinyal}

Pengujian ini dilakukan untuk mengetahui jarak jangkauan sinyal dari wireless router. Pada jarak lebih-kurang 20 meter jangkauan sinyal turun 1 bar. Setelah menggunakan range extension sinyal bar kembali naik 1 bar.

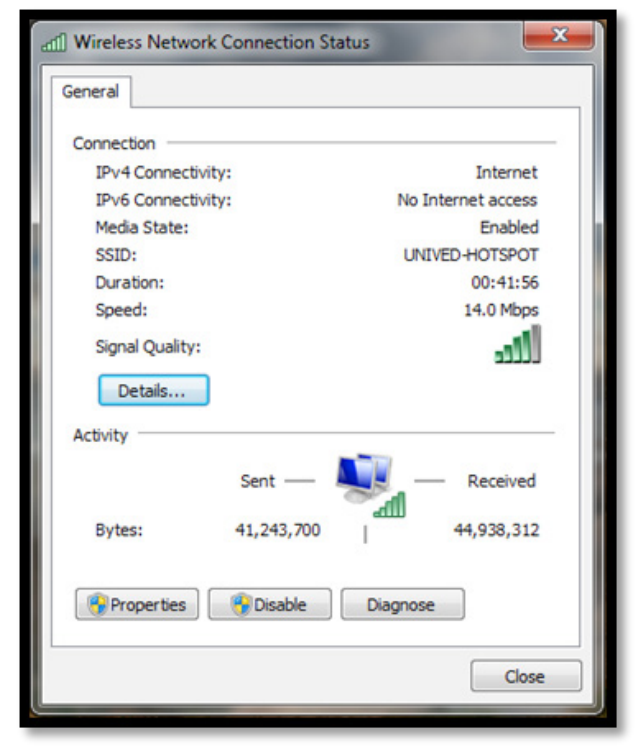

Gambar 4. Sinyal wireless router jarak 20 meter

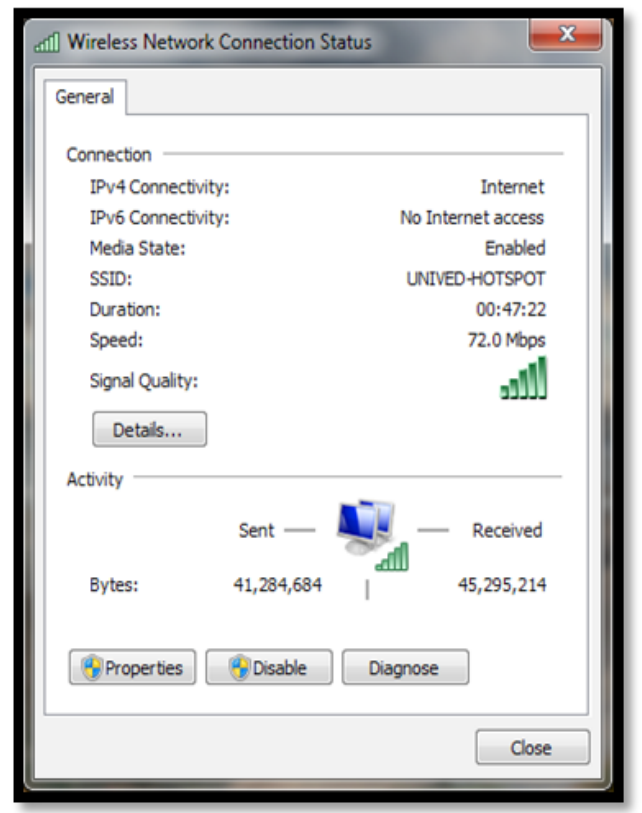

Gambar 5. Sinyal bar setelah range extension 


\section{3) Troubleshooting}

Pengujian ini dilakukan untuk mengetahui kesalahan saat konfigurasi dan koneksi, yaitu :

1. Kesalahan konfigurasi pada wireless router dan range extender. Saat melakukan konfigurasi pada wireless router dan range extender, terjadi kesalahan yaitu wireless router dan range extender tidak bisa terhubung menjadi satu kesatuan. Solusi dari permasalahan ini penulis merubah konfigurasi pada wireless router menjadi AP router-client sehingga range extender bisa terhubung ke wireless router.

2. Kesalahan koneksi kabel pada PoE wireless router. Saat penulis melakukan penelitian ada kesalahan saat mengkoneksikan wireless router dengan PoEnya, kesalahan ini menyebabkan wirelees router tidak bisa menerima IP address dari switch yang ada di Universitas Dehasen Bengkulu. Solusi dari permasalahan ini setelah penulis telusuri ternya terletak pada pemasangan kabel itu sendiri, kemudian pe- nulis merubah letak dari koneksi kabel tersebut menjadi LAN yang terhubung ke switch.

\section{Hasil Pengujian dan Analisa}

Hasil pengujuan berseta analisa dari penelitian ini ditunjukkan pada Tabel 4.

Pada tabel 4 terlihat bahwa hasil pengujian dan analisa terlihat manfaat dari penambahan range extender yang mempunyai fungsi sebagai penyambung sinyal dari wireless router. Sehingga untuk koneksi tidak diperlukan lagi pengkoneksian ulang jika telah berpindah tempat dari wireless router.

\section{KESIMPULAN DAN SARAN}

\section{A. Kesimpulan}

Dari hasil penelitian yang dilakukan, dapat disimpulkan bahwa:

1. Untuk membangun wireless extension point ini minimal membutuhkan 2 buah wireless router, 2 buah wireless ini dapat berupa

Tabel 4. Pengujian dan analisa

\begin{tabular}{|c|c|c|c|c|}
\hline $\mathrm{No}$ & Jenis Pengujian & Kriteria & Hasil & Keterangan \\
\hline \multirow[t]{2}{*}{1} & \multirow[t]{2}{*}{ Pengujian SSID } & $\begin{array}{l}\text { Pada Wireless } \\
\text { Router }\end{array}$ & $\begin{array}{l}\text { Acces point yang di sediakan dari } \\
\text { wireless router bernama "UNI- } \\
\text { VED-HOTSPOT" untuk pertama } \\
\text { kalinya diperlukan koneksi. }\end{array}$ & $\begin{array}{l}\text { SSID pada wireless router } \\
\text { "UNIVED-HOTSPOT". }\end{array}$ \\
\hline & & $\begin{array}{l}\text { Pada Range } \\
\text { Extender }\end{array}$ & $\begin{array}{l}\text { Acces point yang di sediakan dari } \\
\text { range extender juga bernama "UNI- } \\
\text { VED-HOTSPOT" dan tidak perlu } \\
\text { melakukan koneksi ulang karena } \\
\text { sebelumnya sudah terkoneksi dari } \\
\text { wireless router. }\end{array}$ & $\begin{array}{l}\text { Konfigurasi sebelumnya } \\
\text { pada Range Extender bah- } \\
\text { wa SSID-nya sudah di- } \\
\text { sinkronkan dari Wireless } \\
\text { Router. }\end{array}$ \\
\hline 2 & $\begin{array}{l}\text { Jangkauan Si- } \\
\text { nyal }\end{array}$ & $\begin{array}{ll}\text { Jarak } & \text { yang } \\
\text { berbeda } & \text { dari } \\
\text { wireless } & \text { rou- } \\
\text { ter } & \\
\end{array}$ & $\begin{array}{l}\text { Pada jarak lebih-kurang } 20 \text { meter } \\
\text { jangkauan sinyal turun } 1 \text { bar. Setelah } \\
\text { di tambahkan range extension sinyal } \\
\text { bar kembali naik } 1 \text { bar. }\end{array}$ & $\begin{array}{l}\text { Kekuatan sinyal kembali } \\
\text { bertambah. }\end{array}$ \\
\hline 3 & Troubleshooting & $\begin{array}{l}\text { Ke s a la han } \\
\text { saat konfigu- } \\
\text { rasi dan ko- } \\
\text { neksi }\end{array}$ & $\begin{array}{l}\text { Kesalahan konfigurasi pada } \\
\text { Wireless Router dan Range Exten- } \\
\text { der, serta kesalahan koneksi peng- } \\
\text { kabelan pada PoE Wireless Router. }\end{array}$ & $\begin{array}{l}\text { Setelah dilakukan per- } \\
\text { baikan konfigurasi pada } \\
\text { Wireless Router dan Range } \\
\text { Extender, serta memperba- } \\
\text { iki pengkabelan pada PoE } \\
\text { Wireless Router troubles- } \\
\text { hooting teratasi. }\end{array}$ \\
\hline
\end{tabular}


wireless router dan range extender.

2. Wireless extension point ini pada dasarnya difungsikan untuk memperkuat atau menambah jangkauan sinyal wifi dan pada wireless extension point ini tidak memerlukan lagu kabel sebagai penghubung, kecuali pada wireless routernya.

3. Dengan memanfaatkan wireless extension point ini, jangkauan sinyal wifi bisa ditambah dengan jarang yang lebih jauh lagi.

\section{B. Saran}

Setelah melakukan penelitian, penulis ingin menyarankan kepada pembaca pada umumnya, jika ingin membuat wireless extension point, hal pertama yang perlu diperhatikan adalah tempat yang akan di pasang wirelessnya, jika tempat yang akan dipasang banyak dihalangi oleh tembok, maka pembuatan wireless extension akan memerlukan banyak range extender.

Wireless extension point ini sangat baik digunakan untuk menghemat pemakaian kabel untuk koneksi internet, karena wireless extension point ini terhubung ke wireless router tanpa kabel.

\section{DAFTAR PUSTAKA}

Asmadi. 2008. Konsep Dasar Keperawatan. Buku Kedokteran EGC: Jakarta. 198halaman.

Daryanto, 2010, Teknik Jaringan Komputer. Alfabeta, Bandung. 168 halaman

Enterprise, Jubilee. 2010. Rahasia Menjadi Jago Download. Elex Media Komputindo: Jakarta.

Hasan, Hamid Said. 2007. Ilmu Dan Aplikasi Pendidikan. PT. IMTIMA: Jakarta. 236halaman.

Hidayat, Anang, 2007, Strategi Six Sigma, Elex Media Komputindo, Jakarta, 256 Halaman

Kamus Besar Bahasa Indonesia Pusat Bahasa Edisi Ketiga. 2001. Gramedia Pustaka Utama: Jakarta. halaman 1353.
Makinuddin dan Tri Hadiyanto Sasongko. 2006. Analisis Sosial: Bersaksi Dalam Advokasi Irigasi. Yayasan AKATIGA: Bandung. 331 halaman.

Mulyanta, S. Edi. 2005. Pengenalan Protokol Jaringan Wireless Komputer. Andi: Yogyakarta. 272 halaman.

Mulyono, Hasyim, 2008, Buku Pintar Komputer. Kriya Pustaka, Jakarta. 228 Halaman.

Sofana, Iwan. 2013. Membangun Jaringan Komputer. Informatika: Bandung. 553 halaman.

Sutono, 2010,Perangkat Keras Komputer dan Tools Pendukungnya. Modula, Bandung. 208 halaman.

Yani, Ahmad. 2008. Panduan Membangun Jaringan Komputer. Teknik: Bandung. 250 halaman.

Wikipedia, (2013, 16 Agustus). Analisis, Diperoleh 16 September 2015, dari http://id.wikipedia.org/wiki/Analisis

Wikipedia, (2014, 24 Maret). Mikrotik, Diperoleh 17 September 2015, dari http://id.wikipedia.org/wiki/MikroTik

Wilman, R. dan Riyan. 2006. Mengenali dan Mengatasi Kerusakan Software Handphone. Kawan Pustaka: Depok.

Winarno, Edy, Ali Zaki dan SmitDev Community. 2013. Membuat Sendiri Jaringan Komputer. Elex Media Komputindo: Jakarta. 179 halaman. 